Anna Augustyn

Uniwersytet w Bialymstoku

Justyna Anders-Morawska

Uniwersytet Lódzki

Marta Hereźniak

Uniwersytet Lódzki

\title{
Inteligentne zarządzanie dziedzictwem kulturowym w procesie budowania marek miast
}

\section{SMART APPROACH TO CULTURAL HERITAGE MANAGEMENT IN THE PROCES OF CITY BRANDING}

Cel: Celem artykulu jest analiza zmian w podejściu do zarzqdzania dziedzictwem kulturowym $w$ procesie budowania marek miast przy zastosowaniu elementów koncepcji miasta inteligentnego. Ewolucja paradygmatu zarzadzania dziedzictwem od ochrony, poprzez konserwacje po planowanie wymaga od decydentów przyjęcia proaktywnej postawy wobec użytkowników miasta w procesach współdecydowania o definiowaniu $i$ wykorzystywaniu lokalnego dziedzictwa. Wykorzystanie inteligentnych narzędzi w komunikowaniu się z użytkownikami, tworzeniu zasobów, czy dystrybucji dóbr kultury stuży usprawnieniu procesów tworzenia marek miast opartych o kulturę.

Metody: Wchodzac od paradygmatu planowania dziedzictwa, jako modelowego ujęcia nowoczesnej polityki kulturalnej, przeanalizowano dane wtórne dotyczqce praktyk wybranych miast z zakresu zarzqdzania kulturq, które wpisuja się $w$ koncepcję smart city. Dokonano przegladu dobrych praktyk $w$ zakresie inteligentnego zarzqdzania dziedzictwem kulturowym pochodzacych $z$ miast zrzeszonych $w$ sieci miast kreatywnych UNESCO, które z dziedzictwa kulturowego uczynity idee przewodniq swoich marek. Na tym tle zaprezentowano dyskusje na temat aktualnych uwarunkowań budowania marki miasta, traktujac dziedzictwo kulturowe jako jeden z jej najważniejszych komponentów.

Wyniki: W opracowaniu zidentyfikowano metody i narzędzia bazujace na nowych technologiach, które sq najbardziej użteczne $w$ obszarze zarzqdzania dziedzictwem kulturowym jako komponentem marki miasta. Wskazano na kluczowe znaczenie nowych technologii w brandingu miast $w$ obszarze kultury, jako narzędzi, które pozwalaja na najpetniejszq realizację idei partycypacji obywatelskiej $i$ koprodukcji (integracja wymiarów smart living $i$ smart people $w$ polityce kulturalnej miast inteligentnych).

Słowa kluczowe: zarządzanie dziedzictwem kulturowym, smart city, marka miasta

\section{Wstęp}

Przedmiotem analizy w niniejszym artykule jest problematyka zarządzania dziedzictwem kulturowym traktowanym jako proces strategiczny wpisujący się w 
całokształt działań na rzecz budowania marki miasta. Przyjmując za punkt wyjścia trzy paradygmaty planowania dziedzictwa według G. Ashwortha, tj. paradygmat konserwacji, ochrony i zarządzania dziedzictwem, w artykule podjęto próbę umiejscowienia tego procesu $\mathrm{w}$ kontekście budowania wizerunku i reputacji miast. Autorki zauważają, że paradygmat zarządzania dziedzictwem $\mathrm{z}$ jego cechami dystynktywnymi, takimi jak orientacja na bieżące wykorzystanie elementów dziedzictwa kulturowego czy też koncentracja na użytkowniku oraz „współtworzenie” przez niego elementów dziedzictwa, dobrze wpisują się w zarówno w najnowsze tendencje w praktyce budowania marek miast.

Rozważania teoretyczne w obszarze budowania marek terytorialnych koncentrują się wokół takich kategorii jak partycypacja, zaangażowanie czy koprodukcja. W warstwie teoretycznej nastąpiła więc istotna zmiana podejścia do budowania marek terytorialnych, w ramach którego podkreśla się rolę zaangażowania różnorodnych interesariuszy oraz uznaje, że marka miasta jest współwłasnością wszystkich zaangażowanych aktorów. Aby skuteczne zarządzać dziedzictwem, władze lokalne winny podjać współpracę z szeregiem interesariuszy oraz współtworzyć sieci składające się z przedstawicieli podmiotów publicznych, prywatnych i non-profit. Celem takich sieci powinna być identyfikacja, waloryzacja, utrzymanie i promocja materialnych i niematerialnych zasobów miasta.

Z uwagi na postępujący rozwój technologiczny, budowanie marki miasta zorientowanego na kulturę ma miejsce zarówno w sferze rzeczywistej jak i wirtualnej. Stąd ważne i uzasadnione staje się przyjęcie takiego podejścia teoretycznego (a w konsekwencji praktycznego), które pozwala łączyć zarządzanie dziedzictwem z zastosowaniem inteligentnych narzędzi cyfrowych do budowania marek terytorialnych. Demokratyczny potencjał Internetu i technologii cyfrowych stopniowo umożliwia bowiem bardziej otwarte i oddolne tworzenie i rozwój marek terytorialnych, co legitymizuje ten proces $\mathrm{w}$ oczach kluczowych interesariuszy. W kontekście planowania dziedzictwa, przyjęcie takiego podejścia oznacza zarządzanie strumieniami danych i stosowanie interaktywnych narzędzi do wzbogacania doświadczenia użytkownika przy jednoczesnym zachowaniu cennych zasobów kulturowych.

\section{Paradygmaty zarządzania dziedzictwem}

Rozważania nad istotą pojęcia dziedzictwa kulturowego koncentrują się wokół dwóch podstawowych problemów. Pierwszym jest określenie, czym są dobra kultury, zaś drugim ustalenie, na jakich zasadach dane dobro kultury staje się częścią dziedzictwa. Dobrem kultury ujmowanym szeroko może być wytwór człowieka, chociaż także wytwór natury posiadający wartości duchowe. ${ }^{1}$ To szerokie ujęcie obejmuje zarówno materialne, jak i niematerialne wytwory działalności kreatywnej człowieka, funkcjonujące również w sferze symbolicznej $\mathrm{np}$. wyrażającej się nadawaniem szczególnego znaczenia elementom środowiska naturalnego. ${ }^{2}$ Proces uzgadniania, co staje się częścią dziedzictwa kulturowego jest procesem społecznym, w którym wciąż na

\footnotetext{
${ }^{1}$ E. Małachowicz: Konserwacja i rewaloryzacja architektury w środowisku kulturowym, Wrocław 2007.

${ }^{2}$ M. Vecco: A definition of cultural heritage: From the tangible to the intangible, „Journal of Cultural Heritage", Volume 11, Issue 3, July-September 2010, https://doi.org/10.1016/j.culher.2010.01.006, [data dostępu: 16.04.2018].
} 
nowo uzgadnia się, które dobra kultury z racji swojej wartości podlegają ochronie i przekazywaniu kolejnym pokoleniom. W tym znaczeniu dziedzictwo kulturowe jest konstruktem społecznym, budowanym na fundamencie uzgodnionego systemu wartości. Dane dobro kultury może mieć dla społeczeństwa wartość emocjonalną i poznawczą ${ }^{3}$, ale też finansowa, funkcjonalna, czy symboliczną ${ }^{4}$.

Z perspektywy władz miejskich dobra kultury, które stają się elementem dziedzictwa zaczynają być przedmiotem polityki miejskiej, przy czym wieloaspektowość dziedzictwa sprawia, że problemy zarządzania nim nie zamykają się jedynie w polityce kulturalnej, ale przenikają do innych obszarów: polityki gospodarczej, komunalnej, mieszkaniowej, transportowej, społecznej, czy edukacyjnej. Wyodrębnianie nie tylko pojedynczych obiektów, jako zasobów dziedzictwa lokalnego, ale też całych kwartałów, czy części dzielnic sprawia, że planowanie urbanistyczne z uwzględnieniem dziedzictwa staje się też częścią lokalnej polityki rewitalizacji. Akceptacja istnienia takiej sieci relacji w systemie polityk miejskich jest warunkiem przejścia od paradygmatów ochrony i konserwacji do paradygmatu planowania dziedzictwa ${ }^{5}$. Dwa pierwsze paradygmaty za swój cel stawiają zachowanie wybranych dóbr kultury dla przyszłych pokoleń przy jak najmniejszej ingerencji w ich tkankę, przy czym paradygmat ochrony jest pod względem nieingerowania bardziej restrykcyjny. Paradygmat planowania oddaje symbolicznie zasób dziedzictwa użytkownikom, ponieważ jego realizacja wymaga od decydentów zastosowania marketingowego podejścia do zarządzania dziedzictwem. W tym ujęciu powinny więc być realizowane aspekty dotyczące zarządzania miastem, marketingu miasta i współrządzenia (ang. governance). Tabela 1. prezentuje obszary rozbieżności między wskazanymi paradygmatami.

Tabela 1. Różnice między paradygmatami zarządzania dziedzictwem

\begin{tabular}{|c|c|c|c|}
\hline & Paradygmat & & \\
\hline & Ochrona & Konserwacja & Planowanie \\
\hline Przedmiot & Obiekt & Obszar & Produkt miejski \\
\hline Cel & Zachowanie & $\begin{array}{l}\text { Ponowne użytkowanie po } \\
\text { adaptacji do innej funkcji }\end{array}$ & \\
\hline Uzasadnienie & Wartość & Wartość/ponowne użytkowanie & Komodyfikacja \\
\hline Czas & Przeszłość & Przeszłość/teraźniejszość & Teraźniejszość \\
\hline Kryteria & Wewnętrzne & Ochrona w danym celu & $\begin{array}{l}\text { Użytkowanie jako czynnik } \\
\text { determinujący }\end{array}$ \\
\hline Przeszłość & Rzeczywista & Przekazana & $\begin{array}{l}\text { Odniesienie do przeszłości } \\
\text { jako } \\
\text { teraźniejszości }\end{array}$ \\
\hline $\begin{array}{l}\text { Punkt } \\
\text { odniesienia }\end{array}$ & Obiekt chroniony & $\begin{array}{l}\text { Kompromis między ekspertami ds. } \\
\text { ochrony a decydentami } \\
\text { politycznymi }\end{array}$ & Potrzeby użytkownika \\
\hline Zmiana & Niezmienność & Do adaptacji & $\begin{array}{l}\text { Do adaptacji na rzecz } \\
\text { tworzenia nowej wartości } \\
\text { dla użytkownika }\end{array}$ \\
\hline Podmioty & Eksperci & Decydenci & Użytkownicy \\
\hline
\end{tabular}

Źródto: opracowanie własne na podstawie (Ashworth, 2015).

${ }^{3}$ G. Ashworth: Planowanie dziedzictwa, Międzynarodowe Centrum Kultury Kraków, Kraków 2015.

${ }^{4}$ J. Carman: Against Cultural Property: archaeology, ownership and heritage. London: Duckworth 2005.

${ }^{5}$ G. Ashworth: Planowanie dziedzictwa, Międzynarodowe Centrum Kultury Kraków, Kraków 2015. 
Proaktywna postawa wobec zasobów dziedzictwa miasta oznacza, że władze lokalne podejmują decyzję aby twórczo przekształcać przeszłość na rzecz jej współczesnej konsumpcji. Oznacza to też, że zasoby dziedzictwa mogą być tworzone w relacji z użytkownikiem (współprodukcja dzieła przez widownię, interaktywność przestrzeni, w których obcuje się z dziedzictwem). Zakłada się więc, że zasoby podlegają rozwojowi w teraźniejszości, a nie jedynie konserwacji. Kryteria selekcji zasobów do zbioru dziedzictwa są negocjowalne $\mathrm{z}$ użytkownikami - następuje demokratyzacja i subiektywizacja procesu zarządzania dziedzictwem i zmniejszenie roli ekspertów. Zwiększenie liczby interesariuszy w procesie zarządzania dziedzictwem kulturowym sprawia, że staje się ono ważnym tematem strategii zarządzania miastem.

G. Ashworth ${ }^{6}$ proponuje na bazie tych założeń typologię miast w zależności od tego, czy są one zorientowane na przeszłość, ochronę i konserwację, czy na planowanie dziedzictwa. Te pierwsze nazywa miastami historycznymi, te drugie - miastami dziedzictwa. Miasta historyczne małej i średniej wielkości stają się muzeami na otwartym powietrzu, podczas, gdy większe stosują podejście wybiórczej ochrony i rekonstrukcji. Miasta wielofunkcyjne, których tkanka historyczna nie dominuje wizerunkowo często wydzielają funkcjonalnie turystyczne miasto historyczne od nowoczesnego centrum komercyjnego lub w przypadku metropolii tworzą tzw. wyspy dziedzictwa.

Można przyjąć, że miasta funkcjonujące $w$ ramach sieci miast kreatywnych UNESCO realizują w praktyce założenia paradygmatu planowania dziedzictwa $\mathrm{W}$ wybranym przez siebie obszarze: rzemiosła i sztuki ludowej, wzornictwa, filmu, gastronomii, literatury, muzyki, czy mediów. Obecny podział na obszary tematyczne nie wyczerpuje wszystkich kategorii dóbr kultury, pozwala jednak na obserwację praktyk zarządzania dziedzictwem o danej tematyce, zarówno materialnym, jak i niematerialnym. Obecnie sieć zrzesza 180 członków z 72 państw. Zadaniem sieci jest wspieranie miast członkowskich w promowaniu kultury lokalnej jako tworzywa miasta zrównoważonego. UNESCO uznając wagę kultury dla realizacji Agendy dla Zrównoważonego Rozwoju 2030 wskazuje, że liczne inicjatywy na rzecz zrównoważonego rozwoju realizowane są na szczeblu miejskim. Obok sieci miast kreatywnych w strukturach UNESCO funkcjonują też: Sieć Miast Światowego Dziedzictwa, czy Międzynarodowa Koalicja na rzecz Włączających i Zrównoważonych Miast. Inicjatywy realizowane $\mathrm{w}$ ramach wspomnianych sieci wymagają przyjęcia optyki miasta inteligentnego (ang. smart city), zwłaszcza w wymiarach smart living i smart people.

Cele, wpisujące się w koncepcję miasta inteligentnego, które mają realizować miasta kreatywne sieci UNESCO to:

- $\quad$ stymulowanie inicjatyw na rzecz uczynienia z kreatywności istotnego czynnika rozwoju poprzez zawiązywanie partnerstw międzysektorowych,

- wspieranie procesów tworzenia, produkcji i upowszechniania idei, usług i produktów związanych z kultura,

- tworzenie ośrodków i centrów kreatywności i innowacyjności, które poszerzają pole możliwości dla twórców i osób związanych zawodowo z sektorem kreatywnym,

${ }^{6}$ Ibidem. 
- poprawa dostępności do kultury zwłaszcza wśród grup defaworyzowanych,

- integracja zarządzania kulturą i procesami kreatywnymi ze strategią rozwoju miasta.

W dalszej części artykułu zostaną scharakteryzowane szczegółowo narzędzia, które mogą zostać wykorzystane dla inteligentnego zarządzania dziedzictwem kulturowym, jako komponentem marki miejsca.

\section{Dziedzictwo kulturowe jako komponent marki miejsca}

W kontekście przytoczonych powyżej paradygmatów zarządzania dziedzictwem kulturowym, należy odnieść się do jego miejsca i znaczenia $\mathrm{w}$ procesie budowania marek miejskich. W literaturze przedmiotu od dawna panuje pogląd, że kultura oraz jej wytwory materialne i niematerialne stanowią jeden $z$ najważniejszych i najczęściej wykorzystywanych wektorów marek miejsc. ${ }^{8}$ Ikoniczne budynki, postacie, wydarzenia, wzornictwo $\mathrm{i}$ inne wytwory kultury zawsze były uznawane za istotne nośniki tożsamości, a później także marki miasta. Dzieje się tak z co najmniej dwóch powodów.

Po pierwsze, koncepcja marki miast (i innych jednostek terytorialnych) jest silnie związana z pojęciem tożsamości lokalnej. ${ }^{9}$ Tożsamość określonej zbiorowości jest zbudowana między innymi na fundamencie wspólnej przeszłości i pamięci o niej. ${ }^{10}$ Przeszłość ta, rozmaicie przekształcana i interpretowana tworzy dziedzictwo kulturowe, które jest wykorzystywane do realizacji wielu współczesnych celów ${ }^{11}$, takich jak np. budowanie poczucie wspólnoty, przynależności i dumy wśród członków zbiorowości.

Po drugie, kreatywny charakter dziedzictwa kulturowego sprawia, że jest ono doskonałym narzędziem, za pomocą którego miejsca mogą artykułować i wzmacniać taki zestaw skojarzeń, jaki uznają za najbardziej atrakcyjny i pożądany przez interesariuszy. ${ }^{12}$

Analizując miejsce i rolę dziedzictwa kulturowego w budowaniu marek miast, warto zauważyć, że sama koncepcja brandingu miast i marki miejskiej przeszła w ostatnich latach istotną ewolucję, co ma istotne implikacje także dla procesu zarządzania dziedzictwem. Pierwotne rozumienie pojęcia marki miasta z perspektywy promocyjnej oraz traktowanie jej przede wszystkim jako narzędzia komunikacji z turystami i inwestorami zewnętrznymi ustąiły miejsca bardziej złożonemu i holistycznemu rozumieniu procesu budowania marki i zarządzania nią. $\mathrm{W}$ tabeli 2. przedstawiono istotę tradycyjnego i współczesnego podejścia do brandingu miast w ujęciu porównawczym.

\footnotetext{
${ }^{7}$ UNESCO, Creative Cities Network Mission Statement, 2014, https://en.unesco.org/creativecities/sites/creative-cities/files/Mission_Statement_UNESCO_Creative_Cities_Network.pdf [ data dostępu: 3.04.2018].

${ }^{8}$ H. Fan: Branding a place through its historical and cultural heritage: The branding project of Tofu Village in China, Place Branding and Public Diplomacy, November 2014, Volume 10, Issue 4.

${ }_{9}$ M. Kavaratzis, M.J. Hatch: The dynamics of place brands: an identity-based approach to place branding theory, Marketing Theory, 13(1) 2013.

${ }^{10}$ L.A., Hague, Identity and place: a critical comparison of three identity theories, Architectural Science Review 1, 2007.

${ }^{11}$ G. Ashworth, P.J. Larkham (red.): Building a new heritage: tourism, culture and Identity in the New Europe, London 1994.

${ }^{12}$ G. Ashworth, M. Kavaratzis: Why brand the future with the past?. The roles of heritage in the construction and promotion of place brand reputations [w:] Go F., Govers R., (red.), International Place Branding Yearbook: managing Reputational Risk, Londyn 2011.
} 
Tabela 2. Tradycyjne i współczesne podejście do budowanie marki miasta

\begin{tabular}{|c|c|c|}
\hline $\begin{array}{l}\text { Budowanie marki } \\
\text { miasta }\end{array}$ & Ujęcie tradycyjne & Ujęcie współczesne \\
\hline $\begin{array}{l}\text { Perspektywa } \\
\text { teoretyczna }\end{array}$ & Marketingowa & Interdyscyplinarna \\
\hline $\begin{array}{l}\text { Sposób rozumienia } \\
\text { marki }\end{array}$ & $\begin{array}{l}\text { Narzędzie promocji, wizerunek } \\
\text { zewnętrzny }\end{array}$ & $\begin{array}{l}\text { Polityka publiczna, spoiwo społeczności } \\
\text { lokalnej, reputacja „wewnętrzna” i } \\
\text { „zewnętrzna” }\end{array}$ \\
\hline $\begin{array}{l}\text { Cele budowania } \\
\text { marki }\end{array}$ & $\begin{array}{l}\text { Poprawa wizerunku zewnętrznego, } \\
\text { przyciągnięcie turystów, inwestorów. }\end{array}$ & $\begin{array}{l}\text { Poprawa jakości życia mieszkańców, } \\
\text { podniesienie poziomu identyfikacji z } \\
\text { miejscem, aktywizacja społeczności } \\
\text { lokalnej, budowanie wspólnoty, poprawa } \\
\text { wizerunku zewnętrznego, przyciągnięcie } \\
\text { turystów, inwestorów }\end{array}$ \\
\hline Kierunek działań & Na zewnątrz & Na zewnątrz i do wewnątrz \\
\hline Adresaci działań & $\begin{array}{l}\text { Turyści, inwestorzy, zewnętrzna } \\
\text { opinia publiczna }\end{array}$ & $\begin{array}{l}\text { Turyści, inwestorzy, zewnętrzna opinia } \\
\text { publiczna, mieszkańcy i inni interesariusze } \\
\text { wewnętrzni }\end{array}$ \\
\hline $\begin{array}{l}\text { Specyfika procesu } \\
\text { brandingu }\end{array}$ & Odgórny (top-down) & Oddolny (bottom-up), partycypacyjny \\
\hline Właściciel marki & Władze lokalne & $\begin{array}{l}\text { Liczni interesariusze wewnętrzni: } \\
\text { mieszkańcy, lokalne firmy, media, } \\
\text { instytucje etc. }\end{array}$ \\
\hline
\end{tabular}

Jak wynika z powyższego zestawienia, w wymiarze teoretycznym, marki miejskie uznaje się za konstrukty nie ograniczone jedynie do sfery marketingu, lecz mające swoje korzenie w innych dyscyplinach, takich jak zarządzanie publiczne, socjologia, geografia humanistyczna, planowanie przestrzenne $\mathrm{i}$ inne. ${ }^{13}$ Uznanie złożoności $\mathrm{i}$ interdyscyplinarności tego pojęcia pociaga za sobą liczne konsekwencje także w wymiarze praktycznym. Rozumienie marki jako konstruktu silnie zakorzenionego w tożsamości miasta, będącego współwłasnością społeczności lokalnej czyni z jej budowania jedną z polityk publicznych ${ }^{14}$, co z kolei determinuje zakres i charakter jej strategii oraz wyznacza nowe sposoby realizacji celów strategicznych marki.

Rozważania teoretyczne oraz realne działania w obszarze budowania marek terytorialnych koncentrują się w związku z omówionymi wyżej zmianami, wokół takich kategorii jak partycypacja czy koprodukcja, które to pojęcia zastapiły odgórne, nieuwzględniające celów interesariuszy wewnętrznych budowanie marki. ${ }^{15}$ Podkreśla się zatem rolę zaangażowania różnorodnych interesariuszy oraz uznaje, że marka miasta jest współwłasnością wszystkich zaangażowanych aktorów ${ }^{16}$, dopuszczając jednocześnie

\footnotetext{
${ }^{13}$ M. Hereźniak: Place branding and citizen involvement - participatory approach to building and managing city brands, International Studies Interdisciplinary Political And Cultural Journal, Vol. 19, No. 1/2017.

14 J. Eshuis, E. Braun, E.-H. Klijn: Place Marketing as Governance Strategy: An Assessment of Obstacles in Place Marketing and Their Effects on Attracting Target Groups, Public Administration Review, Volume 73, Issue 3, 2013; J. Eshuis, A. Edwards: Branding the City: The Democratic Legitimacy of a New Mode of Governance, Urban Studies, 50(5), 2013.

${ }^{15}$ E.M. Jersand: Inclusive Place Branding. What it is and how to progress towards it, University of Göteborg, School of Business Economics and Law, 2016.

${ }^{16}$ G. Hankinson: Relational Network Brands: Towards a Conceptual Model of Place Brands, Journal of Vacation Marketing, 10(2), 2004, ss.109-21; H. E. Sevin: Understanding cities through city brands. City branding as a social and semantic network, Cities, 38, 2014.
} 
występowanie różnych interpretacji marki i jej różnych wizerunków. ${ }^{17}$ Wynika to ze specyfiki procesu zarówno budowania marki, jak i zarządzania dziedzictwem, w których użytkownik/konsument nie jest biernym odbiorca, ale współtwórca, uprawnionym do własnych przekonań i interpretacji. ${ }^{18}$

Zasadnicza zmiana podejścia do budowania marki miasta polega także na tym, że perspektywa klienta zewnętrznego, któremu tradycyjnie poświęca się najwięcej uwagi w strategiach marek miast coraz częściej jest uzupełniana przez perspektywę klienta wewnętrznego (mieszkańca miasta), którego cele, potrzeby i aspiracje z reguły znacząco odbiegają od potrzeb turystów czy inwestorów. ${ }^{19}$ Wyznacznikiem pozycji marki nie są już więc tylko wskaźniki napływu turystów czy inwestorów, lecz także poziom zadowolenia mieszkańców oraz poziom ich zaangażowania w sprawy miasta.

Zatem, należy uznać, że zarówno zarządzanie dziedzictwem kulturowym, jak i budowanie marki miasta są procesami wymagającymi pogodzenia często sprzecznych celów. Jednym $\mathrm{z}$ nich jest konieczność jednoczesnego promowania elementów dziedzictwa na zewnętrz, poprzez odwoływanie się do jego uniwersalnej wartości, z drugiej zaś wzmacniania regionalizmów na potrzeby społeczności lokalnej. Innym, jest konieczność podkreślania różnorodności kulturowej na potrzeby rynków zewnętrznych przy jednoczesnym wspieraniu spójności społecznej od wewnątrz. Kolejnym wyzwaniem jest zrównoważenie celów kulturalnych osób z zewnątrz (poprzez tworzenie kulturalnych produktów eksportowych) oraz związanych z kulturą celów i potrzeb mieszkańców miasta. ${ }^{20} \mathrm{~W}$ skali międzynarodowej, coraz więcej miast będących silnymi markami terytorialnymi, działa według filozofii „zwrócenia miasta mieszkańcom” poprzez równoważenie interesów interesariuszy wewnętrznych i zewnętrznych. Władze takich miast podejmują próby realizacji tego postulatu na przykład poprzez tworzenie ram prawnych i instytucjonalnych zapobiegających nadmiernej eksploatacji przestrzeni publicznej i dziedzictwa kulturowego przez turystów lub też przez precyzyjne tworzenie oferty kulturalnej, skierowanej do świadomych odbiorców, którzy z poszanowaniem odnoszą się do przestrzeni i specyfiki kulturowej miasta.

Zjawiskiem, którego nie sposób pominąć w kontekście budowania marki miasta przez zarządzanie dziedzictwem kulturowym jest rewolucja technologiczna, która w znacznym stopniu umożliwiła wcielenie $\mathrm{w}$ życie nowych założeń brandingu miejskiego, przedstawionych w niniejszym opracowaniu. Rozwój web 2.0, treści generowanych przez użytkownika (UGC) i technologii mobilnych umożliwił bardziej otwarte i oddolne budowanie i zarządzanie markami miejskimi.

\footnotetext{
${ }^{17}$ B. Merrilees, D. Miller, C. Herington: Multiple stakeholders and multiple city meanings, European Journal of Marketing, 2012, Vol. 46(7-8).

${ }^{18}$ G. Ashworth, M. Kavaratzis: Why brand the future with the past?. The roles of heritage in the construction and promotion of place brand reputations [w:] Go F., Govers R., (red.), International Place Branding Yearbook: managing Reputational Risk, Londyn 2011; E. Braun, M. Kavaratzis, S. Zenker: My city - my brand: the different roles of residents in place branding, Journal of Place Management and Development, 6 (1), 2013.

${ }_{19}$ A. Insch, M. Florek: Place Satisfaction of City Residents: Findings and Implications for City Branding [w:] Ashworth G. J., Kavaratzis M. (red.), Towards Effective Place Brand Management: Branding European Cities and Regions, 2010.

${ }^{20}$ G. Ashworth, M. Kavaratzis: Why brand the future with the past?. The roles of heritage in the construction and promotion of place brand reputations [w:] Go F., Govers R., (red.), International Place Branding Yearbook: managing Reputational Risk, Londyn 2011.
} 
Jak zauważa M. Castels ${ }^{21}$, nowe media, z uwagi na swoja dostępność, globalny obieg treści oraz interaktywność, są narzędziami o niezwykłym demokratycznym potencjale. Jeśli potencjał ten zostanie w pełni wykorzystany, ma szanse nieodwracalnie zmienić sposób w jaki miasta zarząadzają swoimi markami, swoim dziedzictwem kulturowym, a zatem także to w jaki sposób zaspokajają potrzeby swoich interesariuszy.

\section{Zarządzanie w kulturze w świetle koncepcji smart city}

Idea smart city to idea miasta inteligentnego, w którym żyje się łatwiej, lepiej, taniej i przyjemniej. Oznacza miasto efektywnie zarządzane, w którym władze współpracują z mieszkańcami mającymi możliwości realizowania swoich indywidualnych, lokalnych celów. Nie odnosi się to tylko do kwestii rozwiązań technicznych, ale także do nowego stylu zarządzania, planowania, a także w jakimś sensie stylu życia mieszkańców miasta. Smart city to umiejętne łączenie tradycyjnej infrastruktury z nowoczesną technologią, co pozwala na zrównoważony rozwój miast. ${ }^{22}$ Jedna $\mathrm{z}$ bardziej holistycznych definicji, zaproponowana $\mathrm{w}$ literaturze przedmiotu, definiuje smart city, jako miasto które osiąga zrównoważony wzrost gospodarczy oraz wysoką jakość życia przy wykorzystaniu inwestycji w kapitał ludzki i społeczny, połączony z mądrym gospodarowaniem zasobami naturalnymi z wykorzystaniem zasad współrządzenia. ${ }^{23}$

Główny motor rozwoju inteligentnych miast stanowi rozwój przemysłów zaawansowanych technologii oraz przemysłów kreatywnych, mających potencjał tworzenia dobrobytu i miejsc pracy, poprzez produkcję i eksploatację własności intelektualnej, jak również związanej z nimi kultury i przedsiębiorczości. Taki kierunek rozwoju wymaga koncentracji wykwalifikowanych, kreatywnych pracowników oraz wykształconych mieszkańców umiejących tworzyć i wykorzystywać zdobycze technologiczne, jak również wiąże się z koniecznością działań urbanistycznych polegających na rozbudowie infrastruktury miasta, szczególnie komunikacyjnej, zapewnieniu różnorodności usługowej, poprawie przestrzeni miejskiej i stworzeniu wysokiej jakości warunków życia. ${ }^{24}$

Odnosi się to również do sektora kultury, w którym to wraz z rozwojem świata wirtualnego oraz postępem nowych technologii coraz częstsze stają się przedsięwzięcia mające na celu usprawnienie jego funkcjonowania oraz poprawa sprawności zarządzania. Koncepcja smart city zakłada bowiem, że największe korzyści można osiaggnąć dzięki zintegrowanemu rozwojowi wszystkich systemów społecznogospodarczych tj. gospodarki (ang. smart economy), mobilności (ang. smart mobility), zarządzania publicznego (ang. smart governance), ludzi i ich wykształcenia (ang. smart people), sposobu życia (ang. smart living) oraz środowiska przyrodniczego (ang. smart

\footnotetext{
${ }^{21}$ M. Castells: Społeczeństwo sieci, PWN, Warszawa 2011.

${ }^{22}$ A. Augustyn: Smart Cities - kierunek rozwoju miast XXI w. w świetle polityki spójności UE [w:] Dziechciarz T., Krawczyk-Sawicka A. (red.), Miasta Polski na poczqtku XXI wieku. Demografia-Wspótpraca- Samorzqd, Katolicki Uniwersytet Lubelski, Stalowa Wola 2013.

${ }^{23}$ H. Schaffers, N. Komninos, M. Pallot, B. Trousse, M. Nillsson, A. Oliveira: Smart Cities and the Future Internet: Towards Cooperation Frameworks for Open Innovation, https://wwwsop.inria.fr/teams//axis/pages/bestpaper/FIA2011t.pdf, [data dostępu: 03.04.2018].

${ }^{24}$ A. Augustyn: Smart Cities - kierunek rozwoju miast XXI w. w świetle polityki spójności UE, op. cit.
} 
environment), tzw. sześciu filarów koncepcji smart city. ${ }^{25} \mathrm{~W}$ inteligentnym mieście nie ma miejsca na nieprzemyślane działania, za to szybko i skutecznie reaguje się na nowe wyzwania. Takie miasto jest efektywnie zarządzane, a jego władze współpracują z mieszkańcami, którzy mają możliwość realizowania swoich indywidualnych, lokalnych celów.

Analizując zagadnienie zarządzania w sferze kultury i ochrony dziedzictwa kulturowego w kontekście koncepcji smart city, należałoby się odnieść do dwóch jego filarów tj. ludzi (ang. smart people) oraz sposobu życia w miastach (ang. smart living).

Smart people rozumiane jest nie tylko jako rozwój wysokiej jakości kapitału ludzkiego, ale również jako rozwój kapitału społecznego, poprzez wspieranie dialogu społeczno-gospodarczego, partycypację społeczną oraz wykorzystanie potencjału kulturowego i kreatywnego oraz rozwój infrastruktury kultury. To właśnie szczególnie dziedzictwo kulturowe, funkcjonujące w niezwykle dynamicznie zmieniającym się środowisku, wymaga ciagłej troski i nieustannego zaangażowania na wszystkich poziomach organizacji demokratycznego społeczeństwa - od władzy centralnej do obywatela. Skuteczność działań w tym zakresie zależy w dużej mierze od właściwego rozpoznania sytuacji, określenia kierunku i jasnego zdefiniowania celów. Te natomiast, jeśli mają prowadzić do świadomie ukierunkowanego gospodarowania zasobami dziedzictwa wymagają stworzenia systemu współpracy i ciagłego dostosowywania do zmieniających się warunków wewnętrznych i zewnętrznych. Można stwierdzić, iż odpowiedzialne zarządzanie dziedzictwem kulturowym to swego rodzaju sprawdzian umiejętności włączania $\mathrm{w}$ działania na rzecz jego ochrony i racjonalnego wykorzystania różnych osób, organizacji czy instytucji oraz wykorzystywania własnych i cudzych doświadczeń $z$ wielu dziedzin funkcjonowania współczesnej gospodarki i społeczeństwa. ${ }^{26}$

Jednym z przykładów innowacyjnego zaangażowania mieszkańców w rozwój lokalnej kultury są crowdfunding oraz crowdsourcing. Crowdfunding to proces, $\mathrm{w}$ trakcie którego współpracuje większa liczba osób. Decydują się one na wyasygnowanie własnych pieniędzy, na wsparcie wysiłków, projektów oraz wizji innych prywatnych osób, firm, przedsiębiorstw czy organizacji. ${ }^{27}$ Jest to procedura pozyskiwania datków od społeczeństwa, umożliwiająca zgromadzenie kapitału niezbędnego do zrealizowania nowych przedsięwzięć. ${ }^{28} \mathrm{~W}$ celu zrozumienia i oceny potencjału inicjatyw crowfundingowych m.in. Komisja Europejska uruchomiła platformę Crowdfunding4Culture (crowdfundingguides.com) dla instytucji i organizacji kulturalnych zainteresowanych takim rodzajem dofinansowania. Prowadzenie kampanii crowdfundingowej przez sektory kulturalne i kreatywne często służy również celom innym niż finansowanie, takim jak rozwój widowni, zaangażowanie społeczności,

\footnotetext{
${ }^{25}$ D. Stawasz, D. Sikora-Fernandez: Zarzqdzanie w polskich miastach zgodnie z koncepcjq smart city, Placet, Warszawa 2015, ss. 21-22.

26 M. Rozbicka: Zarzadzanie Światowym Dziedzictwem Kulturowym. Warszawa, Narodowy Instytut

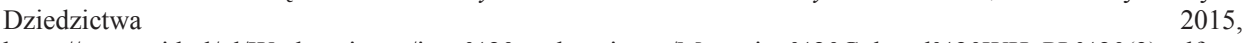
https://www.nid.pl/pl/Wydawnictwa/inne\%20wydawnictwa/Managing\%20Cultural\%20WH_PL\%20(3).pdf , [data dostępu: 13.04.2018].

${ }_{27}^{27}$ A. Brunello: Crowdfunding. Podręcznik, CeDeWu, Warszawa 2015.

${ }^{28}$ S. Steinberg: The Crowdfunding Bible. How to Raise Money for any Startup, Video Game or Project, www.crowdfundingguides.com/The\%20Crowdfunding\%20Bible.pdf, [data dostępu: 12.11.2017].
} 
rozwój umiejętności, promocja i badania rynku, co czyni go ciekawym narzędziem dla wielu działających w tym obszarze podmiotów, również instytucjonalnych. Instytucje kultury coraz chętniej korzystają również z crowdsourcingu czyli mądrości i pracy tłumu do realizacji swoich specyficznych misji, na przykład: ${ }^{29}$

- Transkrypcji i korekty - odbiorcy są zapraszani do poprawiania lub transkrypcji efektów digitalizacyjnych,

- Kontekstualizacji - dodawania kontekstu do zdigitalizowanych obiektów np. poprzez opisywanie historii związanych z danym przedmiotem, czy

- Uzupełniania kolekcji - aktywnego poszukiwania obiektów, które mogą zostać dołączone do przygotowanej przez instytucję digitalizującą kolekcji.

Wśród miast kreatywnych UNESCO tego typu podejście w procesie przygotowywania aplikacji o przyłączenie do sieci zastosował np. York - miasto sztuk medialnych.

Sektor kultury w swej istocie pełni funkcję kapitałotwórczą. Autorzy raportu pt. Kultura lokalnie: między uczestnictwem $w$ kulturze a partycypacja $w$ zarzadzaniu ${ }^{30}$ przeprowadzili badania, których celem było odtworzenie rozumienia uczestnictwa $\mathrm{w}$ kulturze i motywacji towarzyszących konsumpcji kultury. Ze zgromadzonych danych wynika, że członkowie poszczególnych społeczności pośród wielu aspektów motywacyjnych związanych $\mathrm{z}$ organizowaniem dostępu do dóbr i usług kulturalnych wymieniają również dwa dotyczące budowania kapitału kulturowego: integrację społeczności oraz rozwój kompetencji. O potencjale kapitałotwórczym organizacji kulturalnych świadczy stwierdzenie, iż poszczególne osoby traktują przedsięwzięcia kulturalne jako przestrzenie, w których można poznać nowych ludzi i spędzać z nimi czas. Osoba zgadzająca się z tą opinią nie tylko uznaje, że przedsięwzięcie kulturalne przyciaga różnych ludzi, którzy nie mogą mieć ze sobą styczności w codziennym funkcjonowaniu, ale także, że tworzy ono przestrzeń bezpieczną dla wejścia w głębszą interakcję z takim człowiekiem. ${ }^{31}$ Jest to ściśle powiązane z kolejnym, wspomnianym filarem jakim jest smart living.

Smart living rozumieć należy jako proces tworzenia sprawnego systemu wysokiej jakości miejskich przestrzeni publicznych. Miejsc atrakcyjnych i przyjaznych dla bardzo różnych ludzi, harmonijnie łączących różne wątki, wartości i style, bogate różnorodnością, ale równocześnie stanowiące spójną całość. Smart living wiąże się także z dążeniem do procesu budowy i rozwoju lokalnych systemów przestrzeni publicznych, pełniących zróżnicowany, bogaty zestaw funkcji społecznych, zdrowotnych, sportowych, rekreacyjnych i kulturowych.

W odniesieniu do sektora kultury i ochrony jego dziedzictwa rozwój w kontekście wdrażania smart living powiązany powinien być m.in. z:

\footnotetext{
${ }^{29}$ D. Sobolak: Crowdsourcing a digitalizacja - madrość tlumów w cyfrowej kulturze, http://warsztat.org.pl/wpcontent/uploads/2016/03/ekspertyza_crowdsourcing.pdf, (13.04.2018).

${ }^{30}$ W. Kowalik, M. Matlak, A. Nowak, K. Noworól, Z. Noworól: Kultura lokalnie: między uczestnictwem w kulturze a partycypacja w zarzqdzaniu, Małopolski Instytut Kultury, Kraków 2011.

${ }^{31}$ J. Strycharz: Organizacje a rozwój kultury [w:] Hausner J., Karwińska A., Purchla J., Kultura a rozwój. Warszawa: Narodowe Centrum Kultury, http://nck.pl/media/2014-01-21/podrecznik_copy1.pdf, [data dostępu: 13.04.2018].
} 
- usprawnianiem systemu dostepu do kultury obejmującego instytucje publiczne i niepubliczne, z wykorzystaniem nowoczesnych narzędzi teleinformatycznych (ICT),

- ujednolicaniem istniejących systemów informacji kulturalnej,

- usprawnianiem zarządzania miejskimi instytucjami kultury,

- udoskonaleniem systemu monitorowania świadczonych przez miasto w tym zakresie usług,

- budowaniem zintegrowanego systemu informacji i koordynacji wydarzeń kulturalnych w oparciu o zintegrowaną platformę internetową.

Wdrażanie innowacji w sferze kultury wiąże się z pojęciem „kulturotech”, które wywodzi się z założenia, że technologia i kultura są nierozerwalnie ze sobą związane i wywierają na siebie wzajemny wpływ. To kategoria produktów, usług i przeżyć, które powstają w wyniku współoddziaływania kultury, technologii i nauki. Kultura dyktuje kierunek rozwoju technologii, a technologia otwiera nowe możliwości rozwoju wszelkich innych dziedzin (Otwarte innowacje...). Główne założenia kulturotechu to (Otwarte innowacje...):

- wykorzystanie dziedzictwa kulturowego, które cechuje się dużą oryginalnością i niepowtarzalnością (dorobek literacki, historia, bohaterzy, nurty popkulturowe, wyróżniające się wzornictwo, oryginalna myśl naukowa);

- posługiwanie się nowymi technologiami, jako platformą upowszechniania lub narzędziem do współtworzenia treści i doświadczeń „,w skali”;

- wykorzystanie modelu biznesowego, gwarantującego nie tylko utrzymanie i rozwój przedsięwzięcia, ale również wartość niematerialną o charakterze rozwijającym daną markę, produkt czy postrzeganie miejsca z którego się wywodzi;

- zaprojektowanie produktów z założenia przeznaczonych na międzynarodowe rynki. Gdy jest to niemożliwe, jak w przypadku usług publicznych przeznaczonych na rynek lokalny, wykorzystanie skali danej instytucji służy wprowadzeniu znaczącej innowacji w jej obszarze oddziaływania.

Wśród instrumentów opartych na nowoczesnych technologiach współcześnie wykorzystywanych $\mathrm{w}$ inteligentnym rozwoju sektora kultury oraz ochronie dziedzictwa kulturowego wymienić można (tabela 3.): 
Tabela 3. Przykłady instrumentów opartych na nowoczesnych technologiach wykorzystywanych w sektorze kultury i ochronie dziedzictwa kulturowego

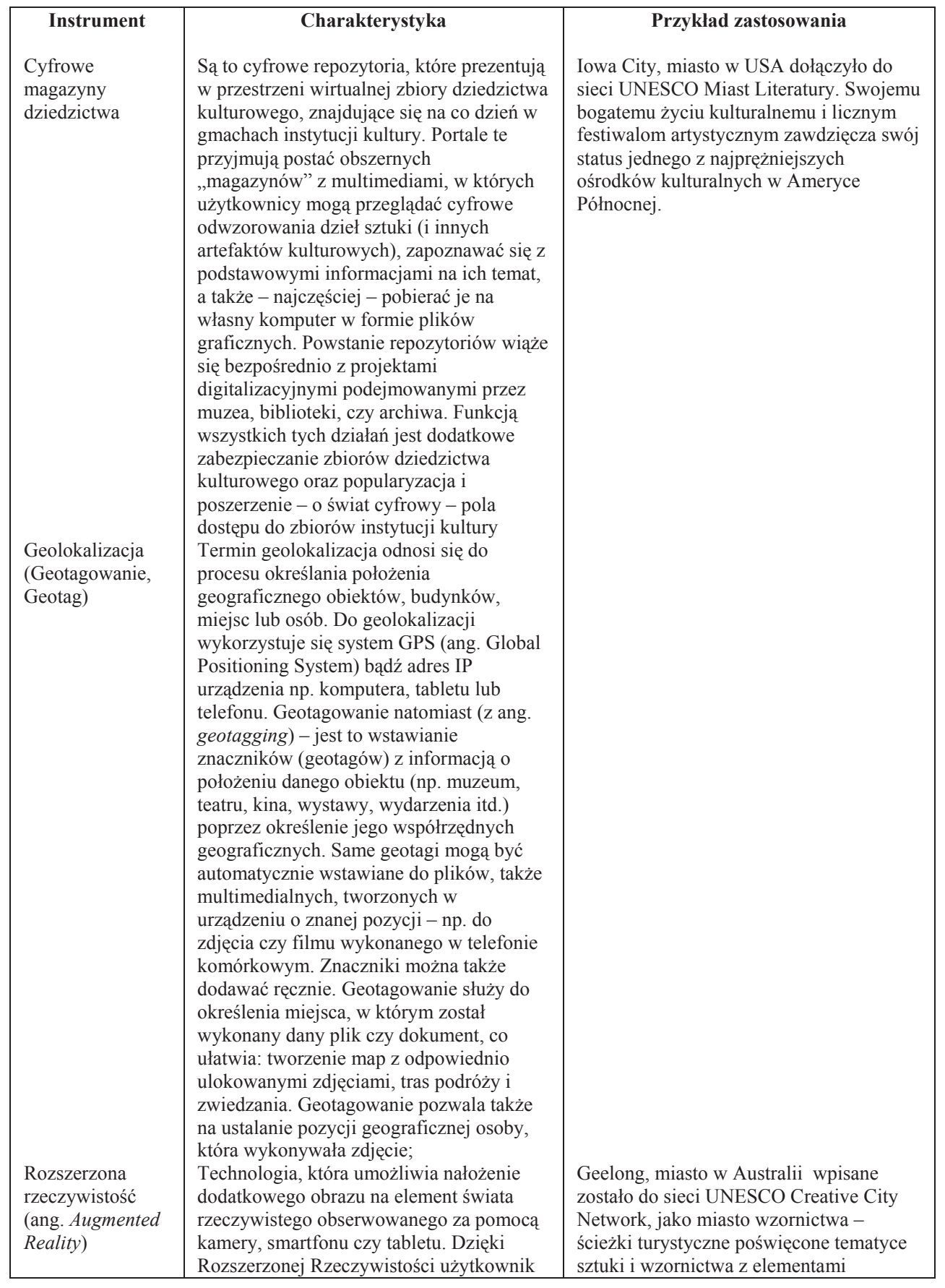




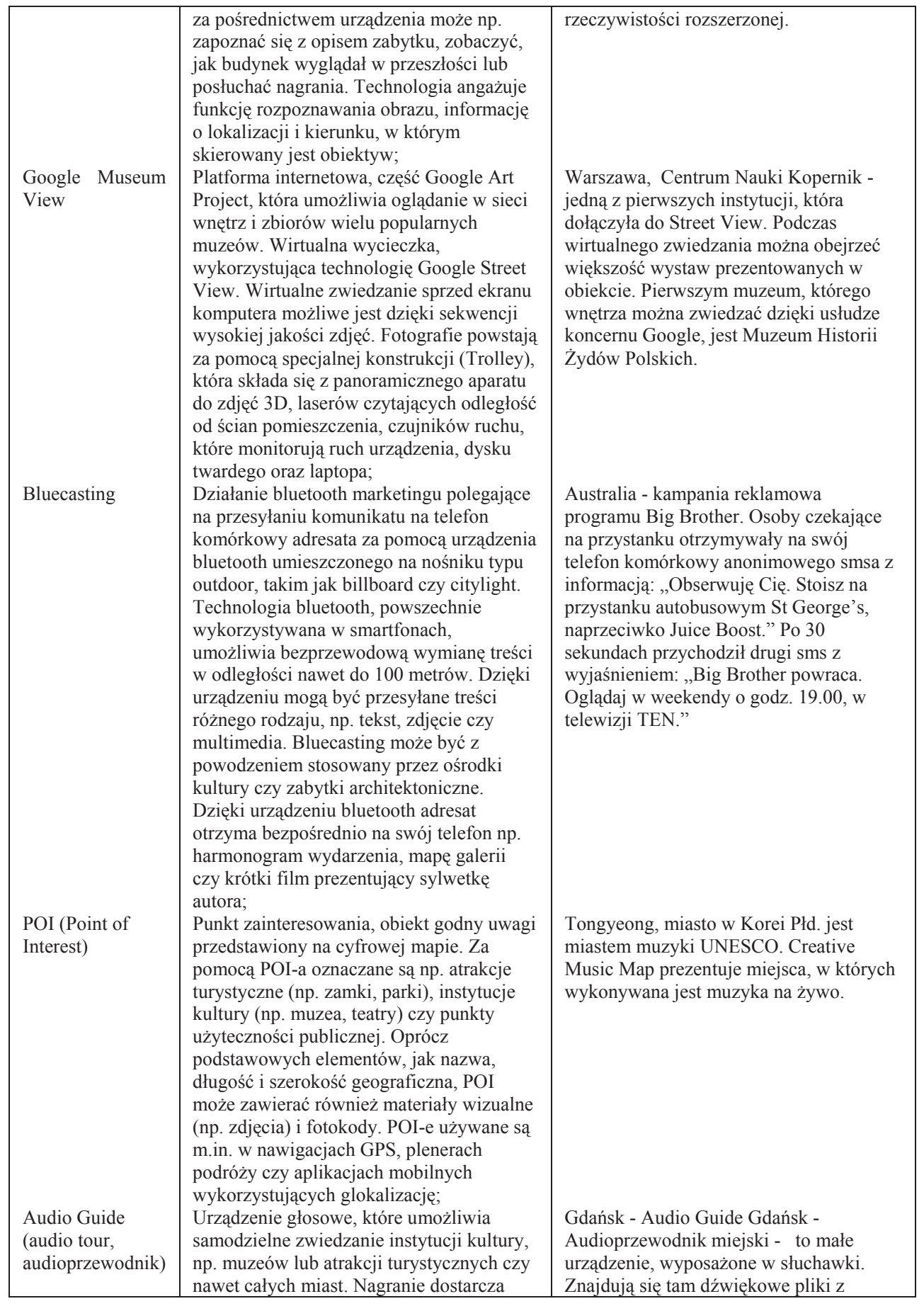




\begin{tabular}{|c|c|c|}
\hline $\begin{array}{l}\text { Google Cultural } \\
\text { Institute }\end{array}$ & $\begin{array}{l}\text { użytkownikom dodatkowych informacji na } \\
\text { temat oglądanych czy zwiedzanych } \\
\text { obiektów, np. sylwetkę autora, interpretację } \\
\text { dzieła sztuki czy okoliczności jego } \\
\text { powstania. Często dostępnych jest kilka } \\
\text { wersji językowych nagrania. Rozwój } \\
\text { mobilnych technologii i rosnąca liczba } \\
\text { użytkowników smartfonów umożliwiły } \\
\text { zastąpienie części tradycyjnych } \\
\text { audioguide'ów aplikacją mobilną } \\
\text { instalowaną na urządzeniu zwiedzającego } \\
\text { czy turysty. } \\
\text { Platforma internetowa koncernu Google, } \\
\text { której celem jest promowanie kultury } \\
\text { poprzez udostępnianie zbiorów online. } \\
\text { Trzy główne sekcje Google Culture } \\
\text { Institute to Google Art Project, Historic } \\
\text { Moments i World Wonders. Dzięki } \\
\text { platformie użytkownik może obejrzeć } \\
\text { dzieła sztuki w bardzo dobrej jakości, } \\
\text { odbyć wirtualną wycieczkę po instytucji, } \\
\text { wziąć udział w wystawie czy „zwiedzić” } \\
\text { miejsca z Listy Światowego Dziedzictwa } \\
\text { UNESCO. }\end{array}$ & $\begin{array}{l}\text { Warszawa - Muzeum Historii Polski } \\
\text { udostępnia zbiory w ramach wystawy } \\
\text { online w Google Culture Institute. }\end{array}$ \\
\hline
\end{tabular}

Źródło: opracowanie własne na podstawie www.kulturainnowacje.pl, [data dostępu: 3.04 .2018 r.]

Wymienione powyżej instrumenty nie wyczerpują szerokiego ich spektrum, stanowią jedynie przykłady. Nieustanny postęp technologiczny, rozwój społeczeństwa informacyjnego, dążenie miast do podnoszenia jakości życia ich mieszkańców powodować będą wdrażanie coraz to nowych narzędzi, które w konsekwencji przysłużą się także do skutecznej ochrony dziedzictwa kulturowego, tak aby mogły się nimi cieszyć i czerpać z ich zasobów również następne pokolenia.

\section{Wnioski}

Funkcjonowanie sieci takich jak Sieć Miast Kreatywnych UNESCO wskazuje, że w świadomości przedstawicieli władz wielu miast dokonuje się istotna transformacja, co do oceny roli dziedzictwa kulturowego w budowaniu marek miast. Wykorzystanie w pełni możliwości, które otwiera marketingowy paradygmat planowania dziedzictwa wymaga od decydentów przyjęcia proaktywnej i otwartej postawy wobec na nowo zdefiniowanego odbiorcy, czy użytkownika dziedzictwa. Zauważalną tendencją jest odwoływanie się do koncepcji miasta inteligentnego, w którym nowoczesne technologie cyfrowe służą podniesieniu jakości życia mieszkańców i budowania unikalnego doświadczenia miasta, zarówno wśród społeczności lokalnej, jak i interesariuszy zewnętrznych (turystów, inwestorów, opinii publicznej). Obydwa wymienione zjawiska przenikają się tworząc nową kategorię miast zorientowanych z jednej strony na rozwój cyfrowej infrastruktury miejskiej i stosujących nowoczesne technologie w wielu obszarach swojego funkcjonowania, z drugiej zaś wyrażających poszanowanie dla dziedzictwa kulturowego jako nośnika własnej tożsamości. 


\section{Bibliografia}

Ashworth G.: Planowanie dziedzictwa, Międzynarodowe Centrum Kultury Kraków, Kraków 2015 Ashworth G., Kavaratzis M.: Why brand the future with the past?. The roles of heritage in the construction and promotion of place brand reputations, [w:] International Place Branding Yearbook: managing Reputational Risk, Go F., Govers R., (red.), Londyn 2011

Ashworth, G., Larkham, P.J. (red.): Building a new heritage: tourism, culture and Identity in the New Europe, London 1994

Augustyn A.: Smart Cities - kierunek rozwoju miast XXI w. w świetle polityki spójności UE [w:] Miasta Polski na poczqtku XXI wieku. Demografia-Wspótpraca- Samorzqd, Dziechciarz T., Krawczyk-Sawicka A. (red.), Katolicki Uniwersytet Lubelski, Stalowa Wola 2013

Braun E., Kavaratzis M., Zenker S.: My city - my brand: the different roles of residents in place branding, Journal of Place Management and Development, 6 (1) 2013

Brunello A.: Crowdfunding. Podręcznik, CeDeWu, Warszawa 2015

Carman J.: Against Cultural Property: archaeology, ownership and heritage, Duckworth, London 2005

Castells M.: Spoleczeństwo sieci, PWN, Warszawa 2011

Eshuis J., Braun E., Klijn E.-H.: Place Marketing as Governance Strategy: An Assessment of Obstacles in Place Marketing and Their Effects on Attracting Target Groups, Public Administration Review, Volume 73, Issue 3, 2013

Eshuis J., Edwards A.: Branding the City: The Democratic Legitimacy of a New Mode of Governance, Urban Studies, 50(5) 2013

Fan H.: Branding a place through its historical and cultural heritage: The branding project of Tofu Village in China, Place Branding and Public Diplomacy, November 2014, Volume 10 , Issue 4

Hague L.A.: Identity and place: a critical comparison of three identity theories, Architectural Science Review 1, 2007

Hankinson G.: Relational Network Brands: Towards a Conceptual Model of Place Brands, Journal of Vacation Marketing, 10(2), 2004

Hereźniak M.: Place branding and citizen involvement - participatory approach to building and managing city brands, International Studies Interdisciplinary Political And Cultural Journal, Vol. 19, No. $1 / 2017$.

Insch A., Florek M.: Place Satisfaction of City Residents: Findings and Implications for City Branding [w:] Towards Effective Place Brand Management: Branding European Cities and Regions, Ashworth G. J., Kavaratzis M. (red.), 2010

Jersand E.M.: Inclusive Place Branding. What it is and how to progress towards it, University of Göteborg, School of Business Economics and Law, Göteborg 2016

Kavaratzis M., Hatch M.J.: The dynamics of place brands: an identity-based approach to place branding theory, Marketing Theory, 13(1), 2013

Kobyliński Z.: Czym jest, komu jest potrzebne i do kogo należy dziedzictwo kulturowe?, MAZOWSZE Studia Regionalne nr 7/2011 23

Kowalik W., Matlak M., Nowak A., Noworól K., Noworól Z., Kultura lokalnie: między uczestnictwem w kulturze a partycypacja w zarzqdzaniu, Małopolski Instytut Kultury, Kraków 2011

Małachowicz E., Konserwacja i rewaloryzacja architektury w środowisku kulturowym, Wrocław 2007.

Merrilees B., Miller D., Herington C.: Multiple stakeholders and multiple city meanings, European Journal of Marketing, 2012, Vol. 46(7-8)

Otwarte innowacje na pograniczu przemystów kreatywnych, nauki i biznesu, Warszawa: Fish Ladder, Platige Image, PwC Polska,

www.nck.pl/media/attachments/319105/otwarte\%20innowacje\%20-\%20raport.pdf 
Rozbicka M.: Zarzadzanie Światowym Dziedzictwem Kulturowym, Warszawa: Narodowy Instytut Dziedzictwa 2015, https://www.nid.pl/pl/Wydawnictwa/inne\%20wydawnictwa/Managing\%20Cultural\%20WH_PL\% 20(3).pdf

Schaffers H., Komninos N., Pallot M., Trousse B., Nillsson M., Oliveira A.: Smart Cities and the Future Internet: Towards Cooperation Frameworks for Open Innovation, https://wwwsop.inria.fr/teams//axis/pages/bestpaper/FIA2011t.pdf

Sevin H.E.: Understanding cities through city brands. City branding as a social and semantic network, Cities, 38 (2014)

Sobolak D.: Crowdsourcing a digitalizacja - madrość tlumów w cyfrowej kulturze,

http://warsztat.org.pl/wpcontent/uploads/2016/03/ekspertyza_crowdsourcing.pdf

Stawasz D., Sikora-Fernandez D.: Zarzqdzanie w polskich miastach zgodnie z koncepcja smart city, Placet, Warszawa 2015

Steinberg S.: The Crowdfunding Bible. How to Raise Money for any Startup, Video Game or Project, www.crowdfundingguides.com/The\%20Crowdfunding\%20Bible.pdf

Strycharz J.: Organizacje a rozwój kultury [w:] Hausner J., Karwińska A., Purchla J., Kultura a rozwój, Warszawa: Narodowe Centrum Kultury, http://nck.pl/media/2014-01-

21/podrecznik_copy1.pdf

Tythacott L., Arvantis K.: Museums and Restitution: New Practices, New Approaches, Routledge 2016

UNESCO, Creative Cities Network Mission Statement, 2014 https://en.unesco.org/creativecities/sites/creative-cities/files/Mission Statement UNESCO Creative Cities Network.pdf Vecco M., A definition of cultural heritage: From the tangible to the intangible, Journal of Cultural Heritage, Volume 11, Issue 3, July-September 2010, https://doi.org/10.1016/j.culher.2010.01.006

Strony internetowe:

1. http://kulturainnowacje.pl/technologie

2. https://www.crowdfunding4culture.eu/

\section{Summary}

Objective: The purpose of this article is to analyse the changes in the approach to cultural heritage management in the context of city brand building by application of smart city concepts. The evolution of the heritage management paradigms from protection, through conservation to planning, requires the city decision-makers to adopt a proactive approach toward city users in the process of local heritage planning. Application of smart tools to communicate with users, to define cultural assets, or to distribute cultural goods facilitates the process of culture-based city branding.

Methods: Treating the paradigm of heritage planning as a normative model of modern cultural policy, the authors analyse secondary data regarding the cultural management activities of selected cities, focusing on the practices that stem from the smart city concept. Selected cites from the UNESCO creative cities network were taken into consideration as those whose brands are based on their cultural heritage. The policies and activities were set in the context of culture-based city branding with smart technologies seen as the vehicles for democratization and participatory character of both: city branding and heritage management.

Findings: The paper identifies 'smart' methods and instruments, applicable and beneficial for the culture-driven city brand building. The new technologies were recognized as a key instrument of city branding in the area of cultural heritage as those that enable to the greatest extent the 
realization of the paradigms of citizen participation and coproduction and allow for the integration of smart living and smart people dimensions in the smart city's cultural policy .

Key words: cultural heritage planning, smart city, city brand

Informacje o autorach:

Dr Anna Augustyn,

Uniwersytet w Białymstoku, Zakład Ekonomiki i Finansów Samorządu Terytorialnego,

ul. Warszawska 63,

15-062 Białystok,

e-mail: a.auugustyn@uwb.edu.pl

Dr Justyna Anders - Morawska,

Uniwersytet Łódzki,

ul. Narutowicza 59a,

90-131 Łódź,

e-mail: justyna.anders@uni.lodz.pl

Dr Marta Hereźniak,

Uniwersytet Łódzki,

ul. Narutowicza 59a,

90-131 Łódź,

e-mail: martaherezniak@uni.lodz.pl 